\title{
CAPTIVE POWER PLANT - A CASE STUDY OF CETP ICHALKARANJI, MAHARASHTRA
}

\author{
D.B.Patil ${ }^{1}$, R.A.Oak ${ }^{2}$, R.H.Jadhav ${ }^{3}$ \\ ${ }^{\text {I}}$ P.G.Student, Bharati Vidhyapeeth Deemed University College of Engineering, Pune, Maharashtra, India. \\ ${ }^{2}$ Ex. CRO, Central Water \& Power Research Station, Pune, Maharashtra, India. \\ ${ }^{3}$ Associate Professor, Bharati Vidhyapeeth Deemed University College of Engineering, Pune, Maharashtra, India
}

\begin{abstract}
Water and wastewater treatment processes requires huge amount of energy in around 30 to $80 \%$ of industrial operation cost. As per this background the water companies needs to identify cost effective and sustainable ways of producing energy. The generated energy should reduce its dependence on fossil fuel and ensure security of power supply. It also helps to reducing the energy cost. Micro hydro power can be available at the doorstep of effluent treatment plant, which has been identified as the solution to a sustainable energy option for the water industry. Nevertheless, there is no option available in literature of hydropower application to water treatment plants. This research gives an overview of hydropower application options available to the water industry consist of water / sewage / Effluent treatment plant. Economics plays an important role in industrial world. The power plants are design on the basis of most economical condition not on the most efficient condition by considering profit and advantage. Effectiveness of the plant is measured financially. The main goal of design and operation of the plant is to bring the cost required for energy production keep minimum as possible. Among many factors, the efficiency of the plant is one of the factors that determine the energy cost. This project measures the feasibility of implementing hydroelectric turbine systems in wastewater treatment facilities in Maharashtra, India. Thus a treatment plant named, Ichalkaranji Textile C.E.T.P. Ltd., Ichalkaranji, District- Kolhapur, Maharashtra, India was selected for a case study analysis. Based on flow and head data, $26 \mathrm{~kW}$ of power could be produced, generating 3.8\% of the facility's electricity needs. Payback periods were calculated to determine hydropower feasibility for other common effluent treatment plants, and $70 \%$ were potentially feasible based on flow but depending on head.
\end{abstract}

Keywords: Hydropower, Captive Power Plant, Effluent, CETP.

\section{INTRODUCTION}

Electric power generation is a state controlled subject. Government has liberalized captive power generation for the user industry to bridge the demand and supply gap. Captive power plants are the power plants set by any person or group of industries to generate electricity for its own resource. It also includes power plant set up by an association or cooperative society. Captive power is the plant that generates required power by itself to the plants by using its own product for power generation. In case of Hydropower plants, they are independent power plant which generates the power by using water as a resource.

Now, private industries are going towards captive generating plants because of financial viability. To minimize the marginal loss of production cost of captive diesel and other non renewable energy generation. More industries high value added for electricity input would naturally insulate them through standby power.

Hydropower is most important new and renewable energy resources. It is helpful for developing energy efficient and clean technology. Worldwide total hydropower capacity is 807 gegawatt with annual generation $3030 \mathrm{TWh} /$ year. Presently, hydropower contributes more than $50 \%$ of electricity supply in about 60 countries.

The current requirement is to promote environmental friendly and sustainable social development. The small scale hydro power plant can be installed at the different sites such as the canal falls, run off river and small streams. Such schemes are amenable for connection to nearby grid. The low head schemes utilize power potential available due to flowing water and head at canal sites. Now, small scale hydro projects have largest contributor in generation of electricity, both at European and world level.

\section{HYDRO POWER PROJECT CLASSIFICATION}

Hydro power project are mainly divided in two categories such as large hydro and small hydro power plant. The categories vary with different countries and having different norms. Hydro power plants categorized as below. : 
Table1-Classification of Hydropower Plants

\begin{tabular}{|l|l|}
\hline \multicolumn{1}{|c|}{ Type } & \multicolumn{1}{c|}{ Capacity } \\
\hline Large hydro power plant & Above 100 MW. \\
\hline Medium hydro power plant & 15 to $100 \mathrm{MW}$. \\
\hline Small hydro power plant & 1 to $15 \mathrm{MW}$. \\
\hline Mini hydro power plant & $\begin{array}{l}\text { Above } 100 \mathrm{KW} \text { and below } \\
1 \mathrm{MW}\end{array}$ \\
\hline Micro hydro power plant & From 5KW to 100 KW \\
\hline Pico hydro power plant & $\begin{array}{l}\text { From a few hundred watts } \\
\text { up to 5kW }\end{array}$ \\
\hline
\end{tabular}

The Ministry of Govt. of India's ministry of NRE i.e. new and renewable energy is the agency planning, financing and installation of small scale hydro project up to $25 \mathrm{MW}$ capacities.

Further classification of small scale hydro power in India is as follows:

Table 2- Classification of small scale hydro plants in India

\begin{tabular}{|l|l|}
\hline Type & Capacity ( kW) \\
\hline Tiny hydro power plant & Less than $1 \mathrm{KW}$ \\
\hline Pico hydro power plant & 1 to $5 \mathrm{KW}$ \\
\hline Micro hydro power plant & 5 to $100 \mathrm{KW}$ \\
\hline Mini hydro power plant & 101 to $2000 \mathrm{KW}$ \\
\hline Small hydro power plant & 2001 to $25000 \mathrm{KW}$ \\
\hline Large hydro power plant & Above $25000 \mathrm{KW}$ \\
\hline
\end{tabular}

\section{GENERAL PRINCIPLES OF SMALL SCALE HYDRO POWER (SHP)}

Generation of power from water mainly depends upon a combination of head and flow of water. Both must be required to be available to generation of electricity. Water is diverted from a stream towards the pipeline, where it is directed through the turbine. The pressure of water at the end of pipeline depends on vertical distance i.e. head. This pressurized water creates force on turbine blade and drives the turbine immediately. The turbine is coupled with generator then power is produced. Amount of electricity produced depends on Quantity of flow of water and available head at site. Amount of power produced i.e. will always be less than the input because of turbine and generator efficiency.

The electric power (theoretical) produced i.e. output at the given head and quantity of water is given by

\section{$\mathbf{P}=\mathbf{Q} \times \mathbf{H} \times \mathbf{e} \times \mathbf{g} \quad$ in Kilowatts $(\mathrm{kW})$}

Where,

$\mathrm{P}=$ Power output in KW,

$\mathrm{H}=$ head available at site in meter.

$\mathrm{Q}=$ Flow in outlet pipe, in meter cube per second $\left(\mathrm{m}^{3} / \mathrm{s}\right)$

$\mathrm{e}=$ the efficiency of the power plant considering total head

loss and efficiency of the turbine and generator, expressed

by a decimal (e.g. $85 \%$ efficiency $=0.85)$ $\mathrm{g}=9.81($ constant $)$ is the product of density of water and acceleration due to gravity.

This available power output will be converted by the hydro turbine in mechanical power.

\section{HYDRO POWER AT TREATMENT PLANT}

There are 88 CETP's (common effluent treatment plants) constructed and commissioned under the CETP scheme of Govt. of India. The Combined capacity of all plants is 760 MLD (Central Pollution Control Board- CPCB) throughout India. . The concept of Common Effluent treatment plant (CETP) was established as a way to treatment of combined wastewater at lower unit cost than that could be achieved by individual industries. The rules for discharge rate monitored by environmental regulatory agencies i.e. MPCB (Maharashtra Pollution Control Board) or CPCB.

The water flowing through these treatment plants provides a potential source of power that may be reclaimed and transformed into electricity. The purpose of this project is to determine the feasibility of implementing a hydroelectric turbine system in the outfall of wastewater treatment facilities in India. The electricity generated from this system may then be used to contribute the energy demand of the treatment plant either through net metering or by selling the electricity back to the supplier. In order to conduct a feasibility study, additional information from treatment plants on such as flow variations, available head and electricity usage was needed from treatment plant. All the treatment plants with flows greater than 10 MLD flow were required because the hydroelectric power generation would be greatest with these relatively high flow ranges.

\section{CASE STUDY: The Ichalkaranji Textile}

\section{C.E.T.P. Ltd}

The case study analysis was conducted on the Ichalkaranji textile CETP Ltd. Ichalkaranji,District-Kolhapur, Maharashtra. Information was gathered from the plant staff, and an estimate of the power potential was created. Then, a turbine was selected, a design was considered, and piping material was chosen.

Ichalkaranji is the Manchester of Maharashtra state. Textile industry has played an important role in the economical development of the city. It consists of a number of small and medium scale textile industries, which are export oriented. Ichalkaranji Textile Common Effluent Treatment Plant Ltd (ICH-CETP) has cluster of 67 processes. Ichalkaranji Textile Development Cluster (ITDC) has established 12 MLD CETP for treatment of effluent to achieve the desired MPCB/CPCB disposal rules and regulations.

The CETP collects wastewater from a number of small and medium scale textile industries has cluster of 67 processes. The effluent of these industries is treated by various processes before it is discharged into the river Panchaganga. The effluents passes through the different units is as follows: 


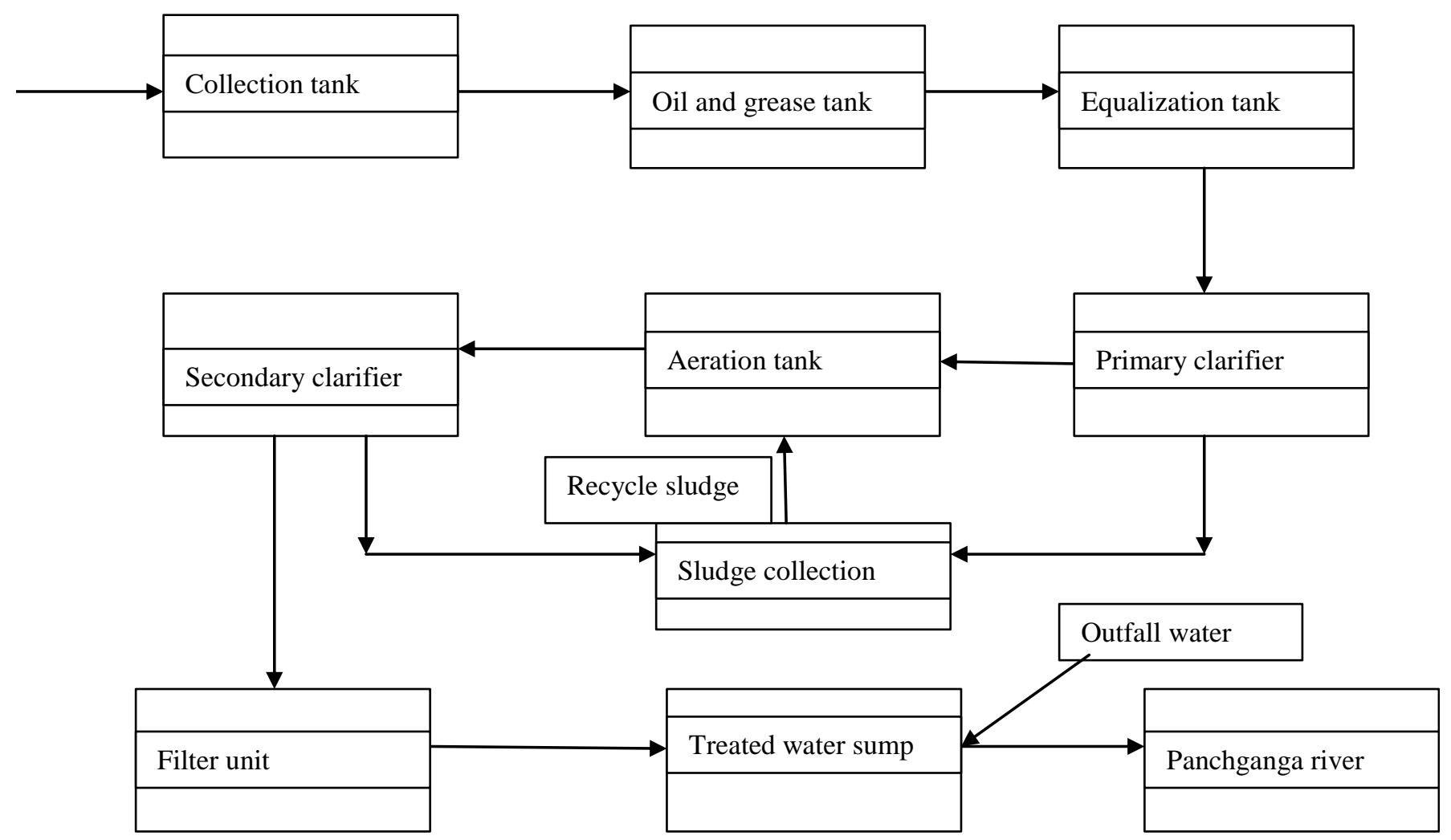

Figure 1. Flow chart of treatment process

In Ichalkaranji CETP, different processes requires huge amount of energy as compared to the industry production cost. As per the information collected from the plant the amount of energy used for the treatment was -

Total energy used for treatment $=824 \mathrm{HP}=53,11,044 \mathrm{kWh}$ or units per year.

Information on the CETP facility was gathered to determine whether the integration of a hydroelectric turbine system was economically viable or not for this site. This information includes flow conditions, dimensions of the tank size, height, effluent channel and discharge outlet, plant electricity costs, and flow data. The effluent flow data and the average electric costs per month for operations were directly obtained from the plant staff. A site visit provided information about the space available to install the turbine, how the treatment plant operates, and the design of the existing effluent channel.

\subsection{POTENTIAL POWER OUTPUT}

As per collected information in the CETP site the flow through the treatment plant is between 0.5 to $0.7 \mathrm{~m}^{3} / \mathrm{s}$. The average flow value was used in power calculations because it provides a long term assessment of power generation capabilities. The treated effluent falls into the effluent outlet channel through outfall pipe. The height or vertical distance between tank water level and outlet channel is $4.8 \mathrm{~m}$. The hydraulic profile consists of elevation information with respect to flow variation of effluent discharge channel at varying time which is measured at site. The CETP hydraulic profile is provided as a supplementary document to this report. The available head is $(4.8 \mathrm{~m})$ measured as the elevation difference from the water height in treated water sump to the water height at the effluent channel.

Based on head, flow, and constants pertaining to the water density, gravitational acceleration, and efficiency value of $85 \%$ was assumed. This value is commonly used for engineering purpose to determine the approximate power generation produced., the power that can be generated from a turbine at the CETP was determined as follows -

Table 3- Flow rate and energy output with Time

\begin{tabular}{|l|l|l|}
\hline TIME & Flow & Output power $(\mathrm{kW})$ \\
\hline 8AM & 0.550 & 21.55 \\
\hline 9AM & 0.560 & 21.94 \\
\hline $10 \mathrm{AM}$ & 0.620 & 24.29 \\
\hline $11 \mathrm{AM}$ & 0.620 & 24.29 \\
\hline $12 \mathrm{AM}$ & 0.645 & 25.27 \\
\hline $1 \mathrm{PM}$ & 0.675 & 26.45 \\
\hline 2PM & 0.725 & 28.41 \\
\hline $3 \mathrm{PM}$ & 0.712 & 27.90 \\
\hline 4PM & 0.715 & 28.02 \\
\hline $5 \mathrm{PM}$ & 0.726 & 28.45 \\
\hline $6 \mathrm{PM}$ & 0.720 & 28.21 \\
\hline
\end{tabular}




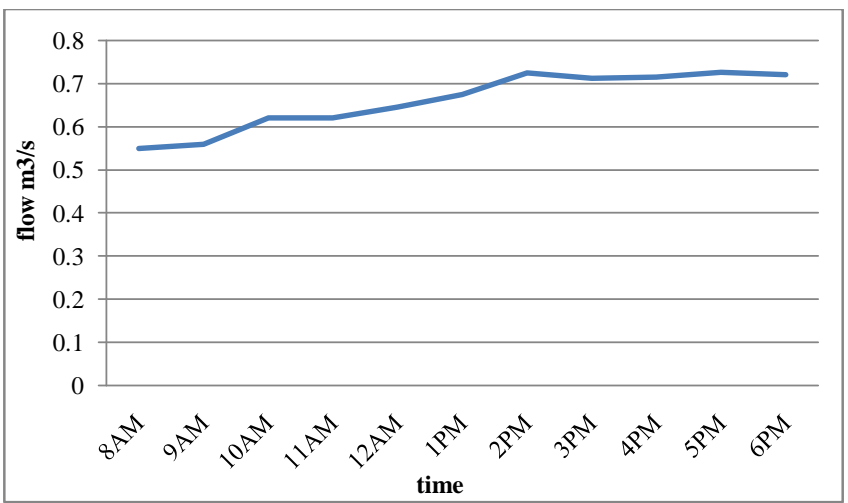

Graph 1- Effluent Flow rate with Time

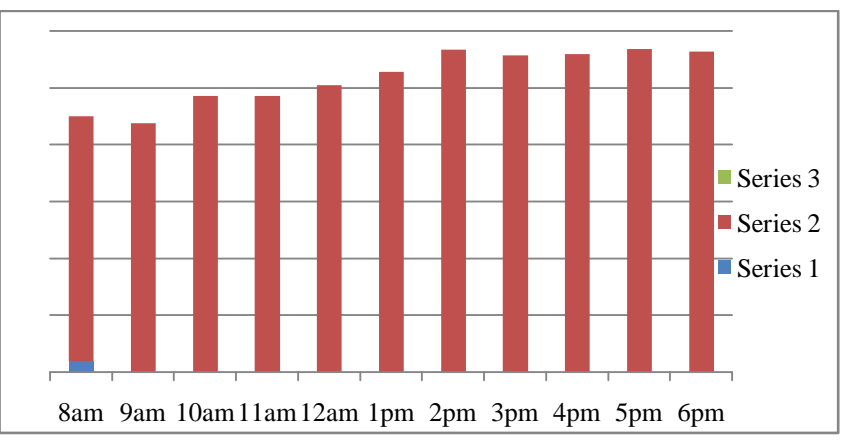

Graph 2-Power generation in $\mathrm{kW} 8$ am to $6 \mathrm{pm}$ (load duration curve)

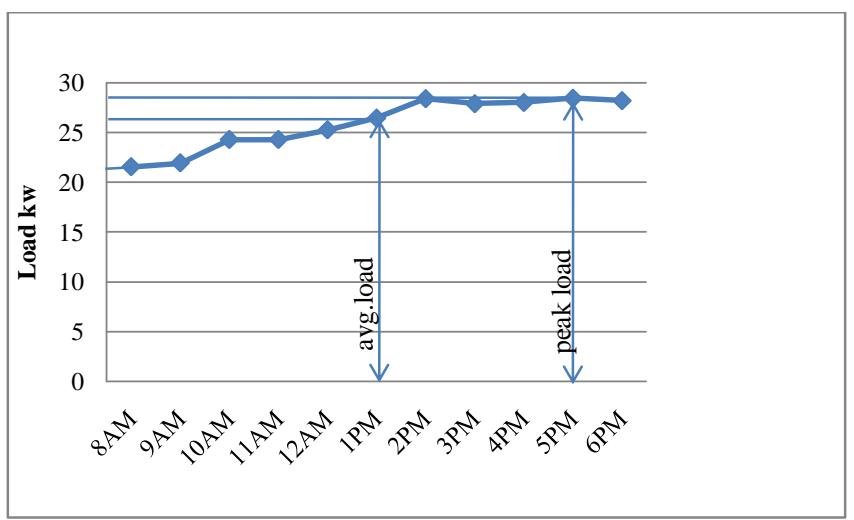

Graph 3- Load Curve

\section{Capacity factor -}

It is obtained by of actual energy produced in kilowatt hours $(\mathrm{kWh})$ divided to the max possible output power that during the same period.

Mathematically,

$=$ avg. annual generation / installed capacity $\mathrm{x}$ hrs per year

$=26 \times 24 \times 365 / 28.45 \times 24 \times 365$

$=0.91$

\section{Annual energy production -}

$=$ Power output $\mathrm{x}$ annual operation time $\mathrm{x}$ capacity factor

$=26 \times 24 \times 365 \times 0.91$

$=2,07,261 \mathrm{kWh}$.

\subsection{TURBINE SELECTION}

Turbines are also be classified by their principle of operation

- Impulse turbines

- Reaction turbines

Table 4- Turbine selection according to head [3]

\begin{tabular}{|l|l|l|l|}
\hline & high head & $\begin{array}{l}\text { medium } \\
\text { head }\end{array}$ & $\begin{array}{l}\text { low } \\
\text { head }\end{array}$ \\
\hline $\begin{array}{l}\text { Impulse } \\
\text { turbines }\end{array}$ & Pelton & cross-flow & cross flow \\
& Turgo & $\begin{array}{l}\text { multi-jet } \\
\text { Pelton }\end{array}$ & \\
\hline $\begin{array}{l}\text { Reaction } \\
\text { turbines }\end{array}$ & & Turgo & \\
\hline
\end{tabular}

Turbine selection generally based on the available water head, and less so on the available flow rate. In general, impulse turbines are used for high head sites, and reaction turbines are used for low head sites.

Kaplan turbines, is a special type propeller turbine, in which the pitch of the blades and the guide vanes can be adjustable. They are well adapted to wide ranges of flow or head conditions, since their peak efficiency can be achieved over a wide range of flow conditions by controlling the gates openings and the pitch angles of the blades. The flow rate at the intended location i.e. CETP Ichalkaranji is relatively constant, hence basic propeller turbine Kaplan type, is more preferable. It helps to increase the robustness of the turbine and to reduce the complication in control.

\subsection{TYPES OF GENERATORS}

For the power range of tens of kilowatt grid connected renewable energy systems, the commonly used generators are:

I) Three-phase synchronous generator

II) Three-phase asynchronous generator (three phase induction generator).

Induction generators are generally more preferable for relatively smaller systems (in tens/hundreds kilowatt, not megawatt scale). They have the advantage of being rugged, almost maintenance free and cheaper than synchronous generators (around 10\% to $25 \%$ lower in price for the range of tens of kilowatt). Induction generators can also allow for a wider variation of shaft speed (hence the water flow rate).

\subsection{TURBINE / GENERATOR}

SET 


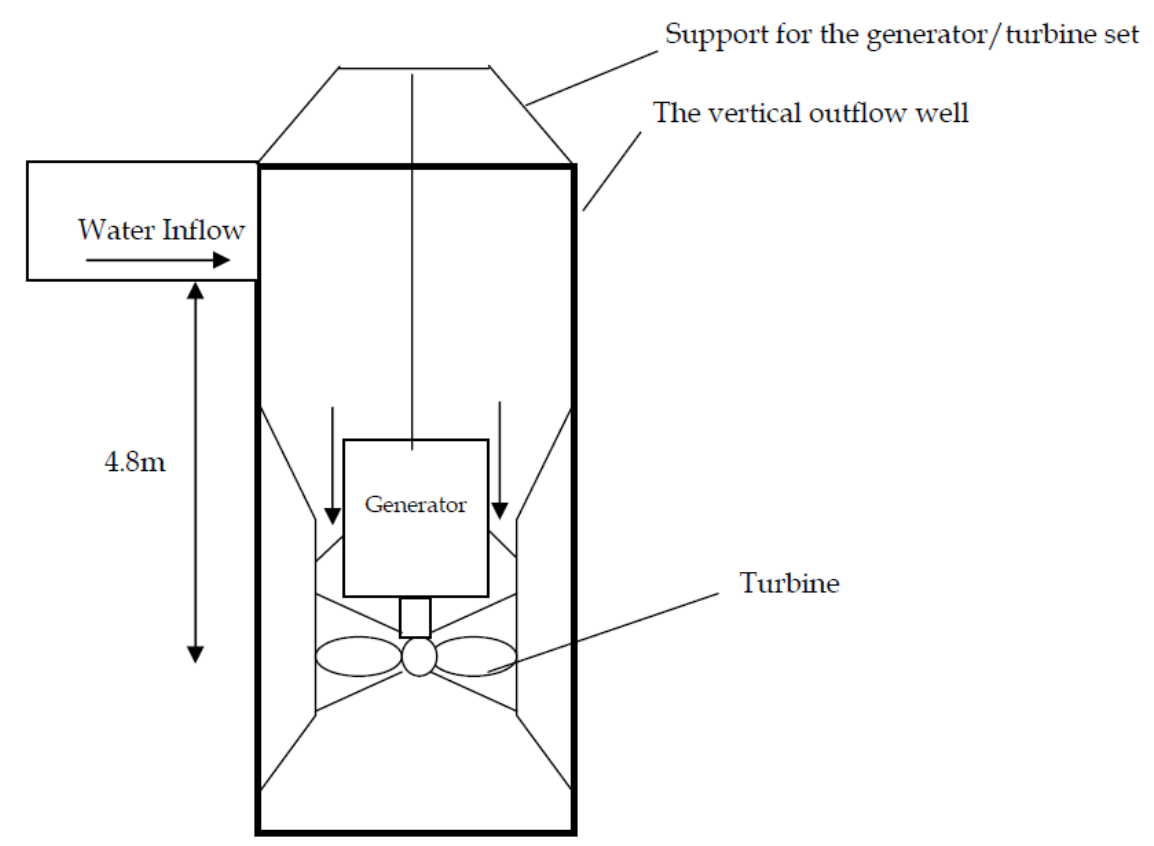

Figure 2. Drawing showing arrangement vertical axis Kaplan turbine and generator

\subsection{CONTROL VALVE/GATE}

The cross-section of the vertical outflow well is rectangular in shape of about $2 \mathrm{~m} \times 1.25 \mathrm{~m}$ with effective length of about
$5.5 \mathrm{~m}$. After the installation of turbine and its guide tube, there is still room at the side for by-passing "surplus" water flow.

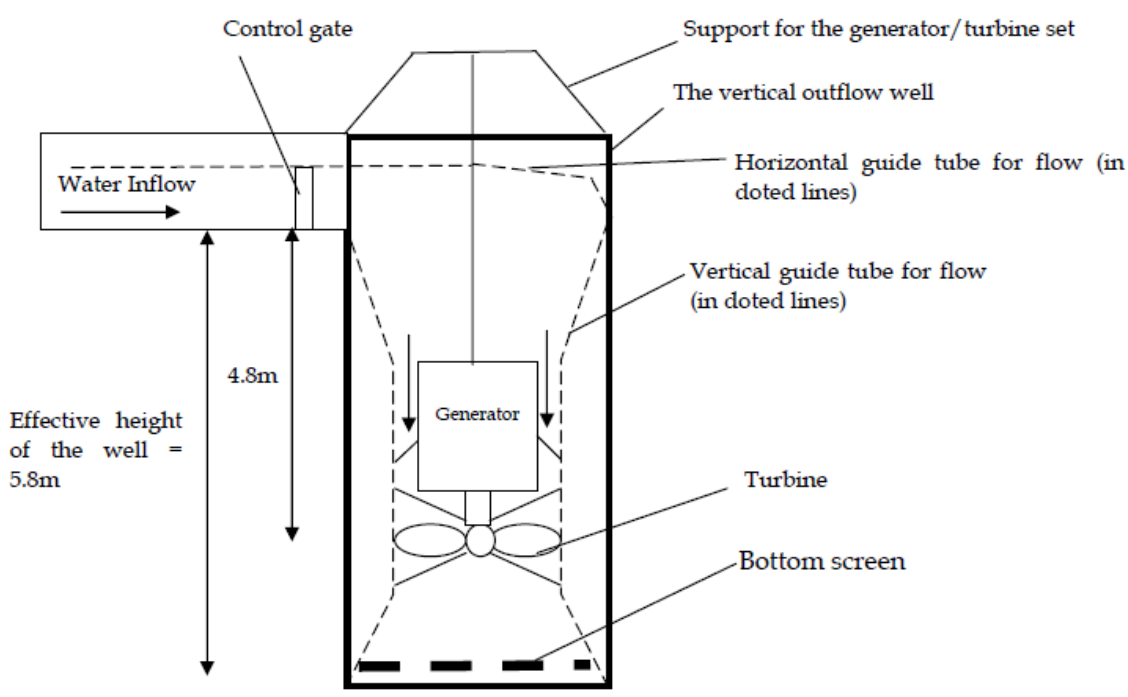

Figure 3. Location of control gate side view

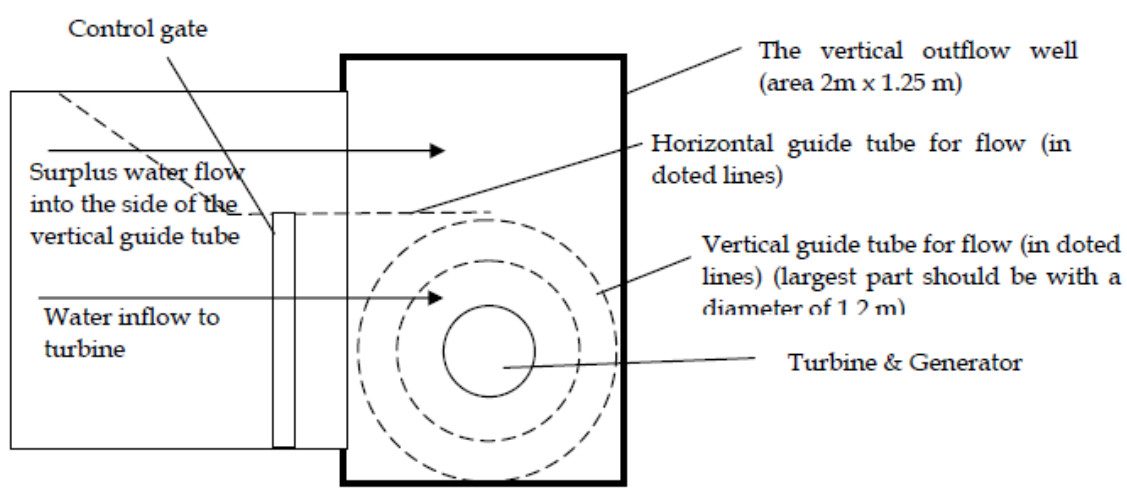

Figure 4. Location of control gate top view 
A control valve/gate will be installed on the top of the vertical outfall well for controlling the water flow into the turbine. Hence control gate helps

1. To start the hydropower system smoothly at the start of the operation and to remove any surge pressure on the turbine.

2. To control the generator set to run at asynchronous speed during the grid- connection process.

3 .After grid connection is made it controls the power output.

4. To ensure that turbine will not run over speed.

\section{ECONOMICS}

The costs that are associated with implementing hydroelectric power generation at a wastewater treatment facility consist of turbine cost, turbine generator set installation cost, piping system cost, and project contingency, which make up the system installation costs. The costs that are associated with implementing hydroelectric power generation at a wastewater treatment facility consist of turbine cost, turbine generator set installation cost, piping system cost, and project contingency, which make up the system installation costs.

The cost of the turbine system consists of turbine itself and generator set, electrical panels grids, transmission cables etc . The fitting for the turbine generator set requires anchors; fasteners are fixed with help of skilled labor. The piping costs are depends on the length and size of the pipe used for the outfall. Costs for the turbine system, anchor fitting, and piping are inclusive of installation fees. After the costs for the turbine generator set and piping system are determined, an interest percentage is added as a safety factor for any blind costs that may occur during the hydro project. A summary of system installation costs for the CETP Ichalkaranji approximately Rs.23,02,000.

Theoretically, hydroelectric turbine at the CETP ichalkaranji would generate $26 \mathrm{~kW}$ at an average flow of $0.65 \mathrm{~m}^{3} / \mathrm{s}$, which is approximately 2,07,261 $\mathrm{kWh}$ of electricity per year.

This generated electricity can be used for the CETP operation which can be save approximately Rs 14,00,000 electricity cost each year. The electricity consumption in 2014 is about 53, 11,044 kWh based on this our micro hydroelectric power system has potential to produce $3.8 \%$ of electricity needs at CETP.

\section{CONCLUSION}

Small scale hydro power is the clean and sustainable energy source can save the exhaustible energy sources. It has the minimum environmental impact as compare to the large hydro power projects. Small scale Micro hydro power plant creates jobs for the worker for the monitoring and operation of power plants. This study useful for implementing small scale power project into other common treatment plants to reclaim the energy at the outfall.

\section{REFERANCES}

[1]. Theophilus Gaius-Obaseki, "Hydropower Opportunities in the Water Industry", International Journal of Environmental Sciences, Volume 1, Issue 3, 2010.

[2]. Jamagoud and Patil, "A Comprehensive Study of Canal Based Mini-Hydro Power Plants", $10^{\text {th }}$ IRF International Conference, Chennai, India, June 2004.

[3]. Gatte and Kadhim, " Hydropower", Report of Hydropower development, Ministry of Science and Technology, Babylon Department, Hilla, Iraq.

[4]. Ranganathan and Mali, "Captive Power Generation: What are the Economics?", Vikalpa, Vol. 12, No. 2, AprilJune 1987.

[5]. Lam, Fung and Cheung, "Application of Hydroelectric Technology in Stonecutters Island Sewage Treatment Works", Report of Research and Development Section, Electrical and Mechanical Projects Division, Drainage Department, Jan 2008.

[6]. Low- Head Hydropower from Wastewater, US EPA report, August 2013.

[7]. Small Hydropower Handbook, Report by Colorado Energy Office, Colorado Government, Denver.

[8]. "Manual and Guidelines for Micro-hydro power development in Rural Electrification", Department of Energy, Philippines, 2009.

[9]. "Hydro-eKids", Micro Hydropower Generating Equipments, Toshiba Engineering. 